\title{
Even Vertex Gracefulness of Fan Graph
}

\author{
A. Solairaju \\ Associate Professor. \\ Jamal Mohamed College \\ Tiruchirappalli-20
}

\author{
P. Muruganantham \\ Head, Department Of Mathematics \\ Kurinji College Of Arts \& Science \\ Tiruchirappalli-02
}

\begin{abstract}
A graph is even vertex graceful if there exists an injective map $f: E(G) \rightarrow\{1,2, \ldots, 2 q\}$ so that the induced map $\mathrm{f}^{+}: \mathrm{V}(\mathrm{G}) \rightarrow\{0,2,4, \ldots, 2 \mathrm{k}-2\} \quad$ defined by $\mathrm{f}^{+}(\mathrm{x})=\sum \mathrm{f}(\mathrm{xy})(\bmod 2 \mathrm{k})$ where $\mathrm{k}=\max \{\mathrm{p}, \mathrm{q}\}$ makes all distinct.
\end{abstract}

In this paper, we prove that Fan graphs $\mathrm{F}\left(\mathrm{nC}_{3}\right)$, $\mathrm{F}\left(\mathrm{nC}_{5}\right)$ and $\mathrm{F}\left(2 \mathrm{nC}_{3}\right)$ are all even vertex graceful, where $\mathrm{n}$ is any positive integer.

Introduction: A.Solairaju, and A.Sasikala [2008] got gracefulness of a spanning tree of the graph of product of $\mathrm{P}_{\mathrm{m}}$ and $\mathrm{C}_{\mathrm{n}}$, A.Solairaju and K.Chitra [2009] obtained edge-odd graceful labeling of some graphs related to paths. A.Solairaju and C.Vimala [2008] also got gracefulness of a spanning tree of the graph of Cartesian product of $S_{m}$ and $S_{n}$,

A.Solairaju and P.Muruganantham [2009] proved that ladder $P_{2} \times P_{n}$ is even-edge graceful (even vertex graceful). They found [2010] the connected graphs $\mathrm{P}_{\mathrm{n}} \mathrm{o} \mathrm{nC}_{3}$ and $\mathrm{P}_{\mathrm{n}} \mathrm{o} \mathrm{nC}_{7}$ are both even vertex graceful, where $\mathrm{n}$ is any positive integer. They also obtained [2010] that the connected graph $\mathrm{P}_{\mathrm{n}} \Delta \mathrm{nC}_{4}$ is even vertex graceful, where $\mathrm{n}$ is any even positive integer.

\section{Section I : Preliminaries}

Definition 1.1: Let $G=(V, E)$ be a simple graph with $p$ vertices and $q$ edges.

$$
\text { A map } \mathrm{f}: \mathrm{V}(\mathrm{G}) \rightarrow\{0,1,2, \ldots, \mathrm{q}\} \text { is }
$$

called a graceful labeling if $\mathrm{f}$ is one - to - one

The edges receive all the labels (numbers) from 1 to $\mathrm{q}$ where the label of an edge is the absolute value of the difference between the vertex labels at its ends.

A graph having a graceful labeling is called a graceful graph.

Definition 1.2: A graph is even vertex graceful if there exists an injective map $f: E(G) \rightarrow\{1,2, \ldots, 2 q\}$ so that the induced map $\mathrm{f}^{+}: \mathrm{V}(\mathrm{G}) \rightarrow\{0,2,4, \ldots, 2 \mathrm{k}-2\}$ defined by $\mathrm{f}^{+}(\mathrm{x})=\sum \mathrm{f}(\mathrm{xy})(\bmod 2 \mathrm{k})$ where $\mathrm{k}=\max \{\mathrm{p}, \mathrm{q}\}$ makes all distinct.

Definition 1.3: A graph is odd-edge graceful if there exists an injective map $f: E(G) \rightarrow\{1,3,5, \ldots, 2 q\}$ so that the induced map $\mathrm{f}^{+}: \mathrm{V}(\mathrm{G}) \rightarrow\{0,1,2,3, \ldots, 2 \mathrm{k}-2\}$ defined by $\mathrm{f}^{+}(\mathrm{x})=\sum \mathrm{f}(\mathrm{xy})(\bmod 2 \mathrm{k})$ where $\mathrm{k}=\max \{\mathrm{p}, \mathrm{q}\}$ makes all distinct. 
Example 1.4: The following connected graph is even vertex graceful.

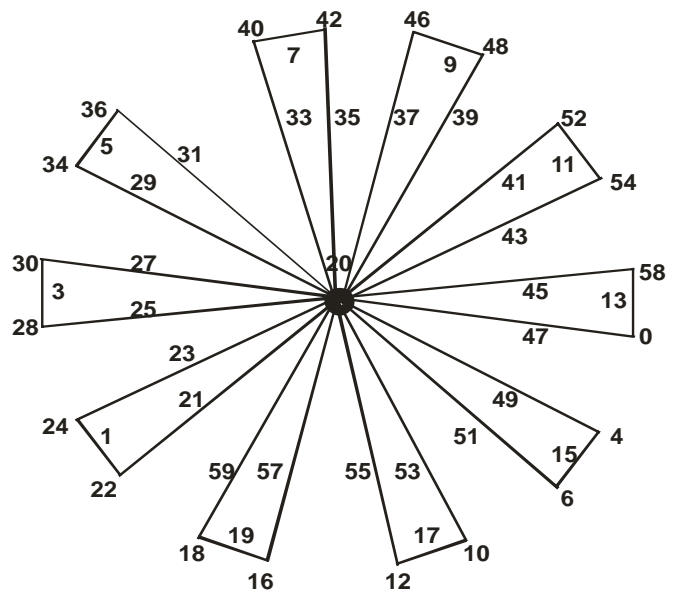

Definition 1.5: A fan graph or a friendship graph $\mathbf{F}\left(\mathbf{n C}_{3}\right)$ is defined as the following connected graph containing $\mathrm{n}$ copies of circuits of each length 3 with some arbitrary labeling of edges.

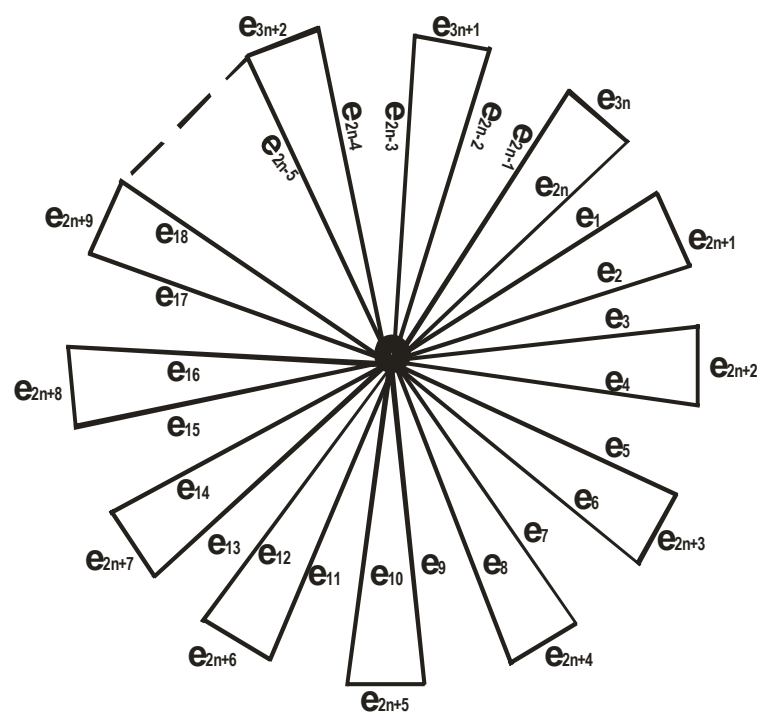

Section 2: Even vertex graceful of fan graph Few contributions on (friendship graph) fan graph are given below.

Notation: $p$ and $q$ denote the number of vertices and edges of a graph respectively.

Theorem 2.1: If $\mathrm{n}=0(\bmod 3)$, the fan graph $\mathrm{F}\left(\mathrm{nC}_{3}\right)$ is even vertex graceful.

Proof: The graph $\mathrm{F}\left(\mathrm{nC}_{3}\right)$ is chosen with some arbitrary labeling of edges as in definition (1.5).
Define a map f: $\mathrm{E}\left[\mathrm{F}\left(\mathrm{nC}_{3}\right)\right] \rightarrow\{0,1,2, \ldots, 2 \mathrm{q}\}$ by $f\left(e_{i}\right)=(2 i-1), i=1, \ldots, 3 n$.

Then the induced map $\mathrm{f}^{+}(\mathrm{u})=\sum \mathrm{f}(\mathrm{uv})$ $(\bmod 2 q)$ where the sum runs over all edges uv through v. Now, $f$ and $\mathrm{f}^{+}$both satisfy even vertex graceful labeling as well as edge-odd graceful labeling. Thus the connected graph $\mathrm{F}\left(\mathrm{nC}_{3}\right)$ is both even vertex graceful and odd-edge graceful.

Theorem 2.2: If $n=1(\bmod 3)$, the fan graph $\mathrm{F}\left(\mathrm{nC}_{3}\right)$ is even vertex graceful.

Proof: The graph $\mathrm{F}\left(\mathrm{nC}_{3}\right)$ is chosen with some arbitrary labeling of edges as in the following diagram.

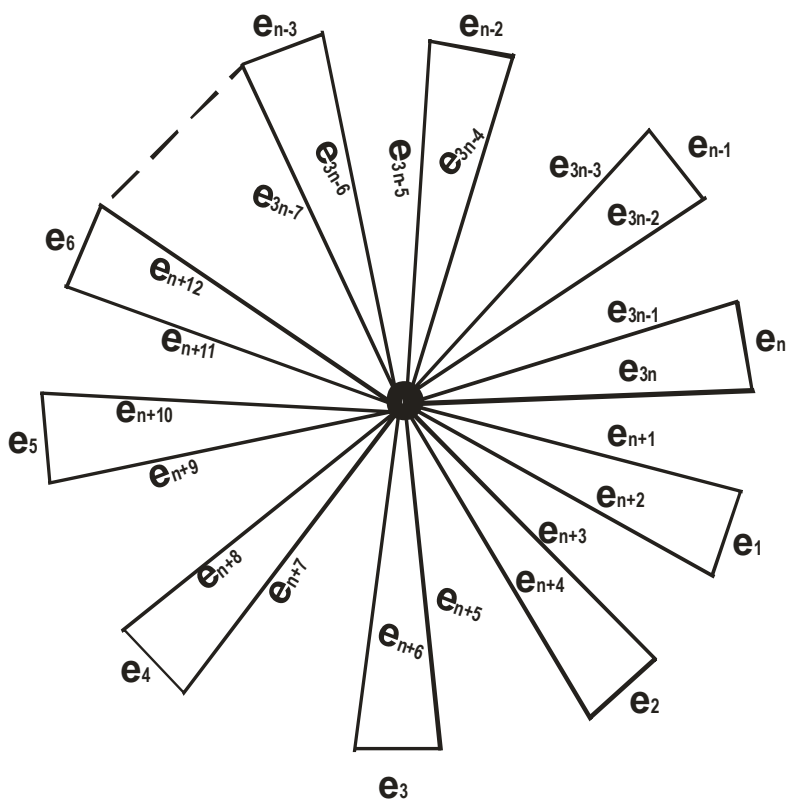

Define a map f: $\mathrm{E}\left[\mathrm{F}\left(\mathrm{nC}_{3}\right)\right] \rightarrow\{0,1,2, \ldots, 2 \mathrm{q}\}$ by $\mathrm{f}\left(\mathrm{e}_{\mathrm{i}}\right)=2 \mathrm{i}, \quad \mathrm{i}=1, \ldots, 3 \mathrm{n}$.

Then the induced map $\mathrm{f}^{+}(\mathrm{u})=\sum \mathrm{f}(\mathrm{uv})(\bmod 2 \mathrm{q})$ where the sum runs over all edges

uV through $\mathrm{v}$. Now, $\mathrm{f}$ and $\mathrm{f}^{+}$both satisfy even vertex graceful labeling. Thus the connected graph $\mathrm{F}\left(\mathrm{nC}_{3}\right)$ is even vertex graceful . 
Theorem 2.3: If $n=2(\bmod 3)$, the fan graph $\mathrm{F}\left(\mathrm{nC}_{3}\right)$ is even vertex graceful.

Proof: The graph $\mathrm{F}\left(\mathrm{nC}_{3}\right)$ is chosen with some arbitrary labeling of edges as in the following diagram.

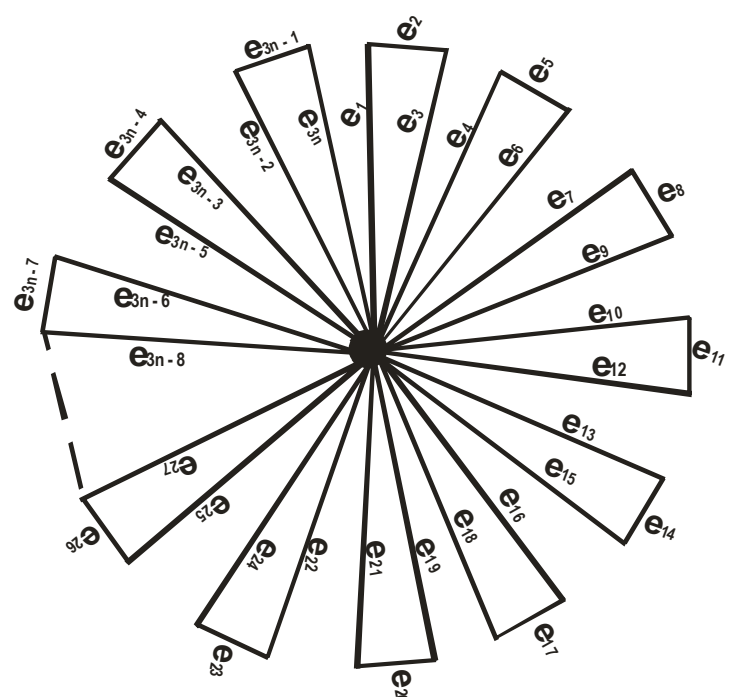

$f\left(e_{i}\right)=2 i$ for $i=1,2,3 ; f\left(e_{i}\right)=(2 i-1), i=4,5,6$;

$\mathrm{f}\left(\mathrm{e}_{\mathrm{i}}\right)=(2 \mathrm{i}-6), \mathrm{i}=7,8,9,13,14,15, \ldots,(3 \mathrm{n}-5)$,

$(3 n-4),(3 n-3)$.

$f\left(e_{i}\right)=2 i-7, i=10,11,12, \ldots,(3 n-8),(3 n-7)$,

(3n-6).

Subcase $(\mathbf{a}): \mathrm{n} \equiv 2(\bmod 3) \equiv 2(\bmod 6)$

$f\left(e_{3 n-1}\right)=2 q, f\left(e_{3 n}\right)=(2 q-4), f\left(e_{3 n-2}\right)=(2 q-8)$.

Subcase $(b): \mathrm{n} \equiv 2(\bmod 3) \equiv 5(\bmod 6)$

$f\left(e_{3 n-1}\right)=2 q, f\left(e_{3 n}\right)=(2 q-2), f\left(e_{3 n-2}\right)=2 q-6$.

Then the induced map $\mathrm{f}^{+}(\mathrm{u})=\sum \mathrm{f}(\mathrm{uv}) \quad(\bmod 2 \mathrm{q})$ where the sum runs over all edges uv through $\mathrm{v}$. Now, $\mathrm{f}$ and $\mathrm{f}^{+}$both satisfy even vertex graceful labeling. Thus the connected graph $\mathrm{F}\left(\mathrm{nC}_{3}\right)$ is even vertex graceful.

Main theorem 2.4: The fan graph $\mathrm{F}\left(\mathrm{nC}_{3}\right)$ is even vertex graceful.

\section{Section 3 - Even vertex graceful of fan graph}

$\mathbf{F}\left(\mathbf{n C}_{5}\right)$.

Definition 3.1: The fan graph $\mathrm{F}\left(\mathrm{nC}_{5}\right)$ is a defined as the following connected graph containing $n$ copies of circuits of each length 5 with some arbitrary labeling of edges.

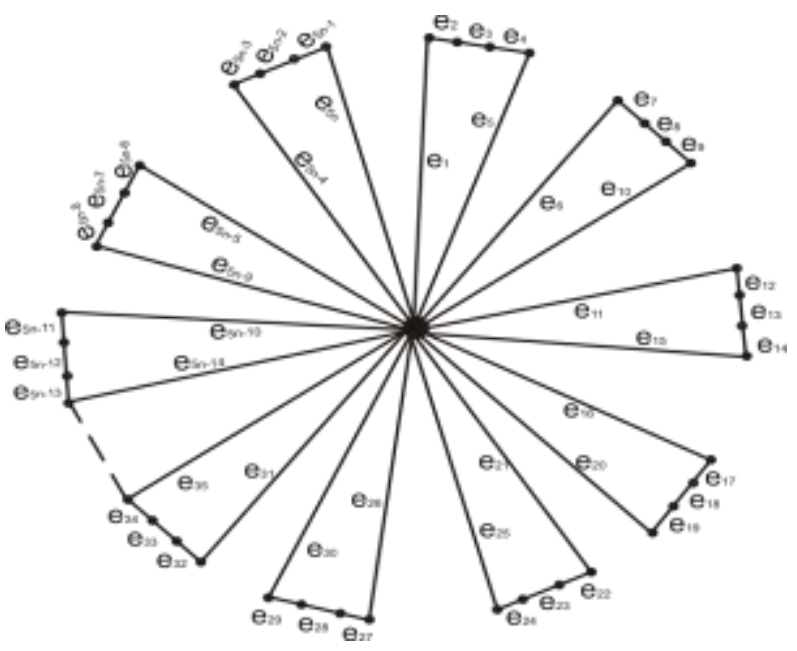

Theorem 3.1: The fan graph $\mathrm{F}\left(\mathrm{nC}_{5}\right)$ is even vertex graceful.

Proof: An arbitrary labeling of edges of $\mathrm{F}\left(\mathrm{nC}_{5}\right)$ is followed from definition (3.1).

Define $\mathrm{f}: \mathrm{E}\left(\mathrm{F}\left(\mathrm{nC}_{5}\right)\right) \rightarrow\{1,2, \ldots, 2 \mathrm{q}\}$ in the following manner:

\section{Case (i) $n$ is odd}

$$
\mathrm{f}\left(\mathrm{e}_{\mathrm{i}}\right)=(2 \mathrm{i}-1), \quad \mathrm{i}=1,2,3, \ldots, \mathrm{q} .
$$

Case (ii) $n$ is even

$$
\begin{array}{ll}
\mathrm{f}\left(\mathrm{e}_{\mathrm{i}}\right)=2(\mathrm{i}+2), & \mathrm{i}=1,2,3,4,5 ; \\
\mathrm{f}\left(\mathrm{e}_{10 \mathrm{k}+\mathrm{i}}\right)=\mathrm{f}\left(\mathrm{e}_{\mathrm{i}}\right)+10 \mathrm{k}, & \mathrm{k}=1,2, \ldots,(\mathrm{n} / 2), \\
\mathrm{i}=1,2,3,4,5 ; \\
\mathrm{f}\left(\mathrm{e}_{\mathrm{i}}\right)=(2 \mathrm{i}-11), \\
\mathrm{f}\left(\mathrm{e}_{10 \mathrm{k}+\mathrm{i}}\right)=\mathrm{f}\left(\mathrm{e}_{\mathrm{i}}\right)+(10 \mathrm{k}), \mathrm{k}=1,8,9,10 ; \\
\mathrm{i}=6,7,8,9,10 .
\end{array}
$$

Then the induced map $\mathrm{f}^{+}(\mathrm{u})=\sum \mathrm{f}(\mathrm{uv})(\bmod 2 \mathrm{q})$ where the sum runs over all edges uv through $\mathrm{v}$. Now, $\mathrm{f}_{\text {and }} \mathrm{f}^{+}$both satisfy even vertex graceful labeling. Thus the connected graph $\mathrm{F}\left(\mathrm{nC}_{5}\right)$ is even vertex graceful

Definition 3.2: The fan graph $\mathrm{F}\left(2 \mathrm{nC}_{3}\right)$ is a defined as the following connected graph containing 2 n copies of circuits of each length 3 with some arbitrary labeling of edges. 


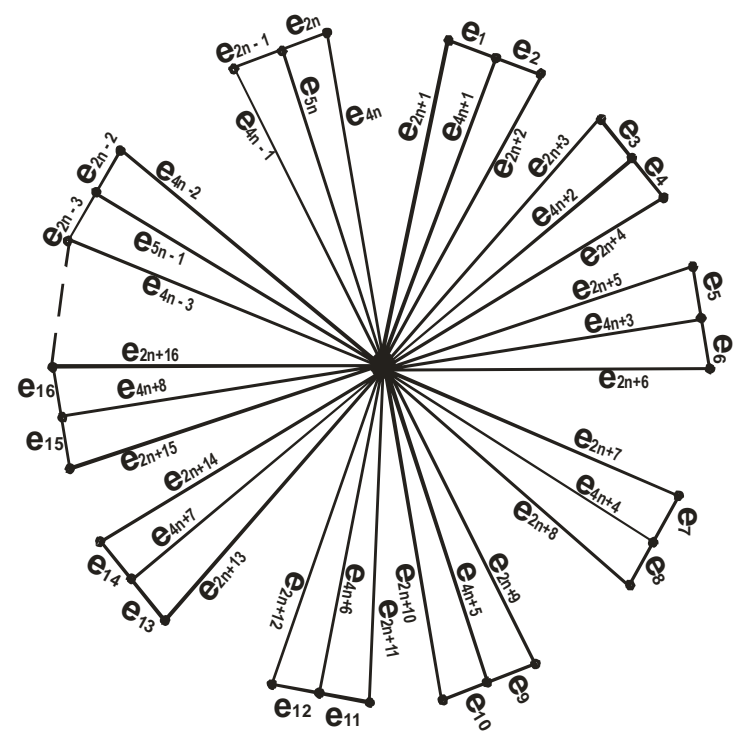

Theorem 3.2: The fan graph $\mathrm{F}\left(2 \mathrm{nC}_{3}\right)$ is even vertex graceful.

Proof: An arbitrary labeling of edges of $\mathrm{F}\left(2 \mathrm{nC}_{3}\right)$ is followed from the definition (3.2).

Define $f: \mathrm{E}\left(\mathrm{F}\left(2 \mathrm{nC}_{3}\right)\right) \rightarrow\{1,2, \ldots, 2 \mathrm{q}\}$ in the following manner:

$\mathrm{f}\left(\mathrm{e}_{\mathrm{i}}\right)=2 \mathrm{i}, \mathrm{i}=1,2,3, \ldots, 4 \mathrm{n}$;

Case (1) $\mathrm{n} \geq 8$ and $\mathrm{n}$ is even : $\mathrm{f}\left(\mathrm{e}_{4 \mathrm{n}+\mathrm{i}}\right)=(2 \mathrm{q}-$ $4 i), i=1,2,3, \ldots, n$.

Case $(2) n \equiv 1(\bmod 4): f\left(e_{4 n+i}\right)=2 q-8(i-1)$, $\mathrm{i}=1,2,3, \ldots, \mathrm{n}$.

Case $(3) n \equiv 3(\bmod 4): f\left(e_{4 n+1}\right)=(2 q-2)$; $f\left(e_{4 n+i}\right)=f\left(e_{4 n+1}\right)-8(i-1), i=2,3, \ldots, n$.

Then the induced map $\mathrm{f}^{+}(\mathrm{u})=\sum \mathrm{f}(\mathrm{uv})$ (mod $2 q)$ where the sum runs over all edges uv through $\mathrm{v}$. Now, $\mathrm{f}$ and $\mathrm{f}^{+}$both satisfy even vertex graceful labeling. Thus the connected graph $\mathrm{F}\left(2 \mathrm{nC}_{3}\right)$ is even vertex graceful.

\section{REFERENCES:}

1. A. Solairaju and K.Chitra, Edge-odd graceful labeling of some graphs, Electronics Notes in Discrete Mathematics Volume 33, April 2009, pp. 15.

2. A. Solairaju and P.Muruganantham, evenedge gracefulness of ladder, The Global Journal of Applied Mathematics \& Mathematical Sciences(GJ-AMMS). Vol.1.No.2, (July-December2008):pp.149-153.

3. A. Solairaju and P.Muruganantham, even vertex gracefulness of path merging circuits, Indian Journal of Mathematics and Mathematical Sciences, Vol. 6, No.1, (June, 2010), pp. $27-31$.

4. A. Solairaju and P.Muruganantham, even vertex gracefulness of even number of copies of $\mathrm{C}_{4}$, accepted for publication in Serials Publications, New Delhi, India.

5. A.Solairaju, and A.Sasikala, Gracefulness of a spanning tree of the graph of product of $\mathrm{Pm}_{\mathrm{m}}$ and ${ }_{\mathrm{Cn}}$, The Global Journal of Pure and Applied Mathematics of Mathematical Sciences, Vol. 1, No-2 (July-Dec 2008): pp 133-136.

6. A.Solairaju, and C.Vimala, Gracefulness of a spanning tree of the graph of Cartesian product of $S_{m}$ and $S_{n}$, The Global Journal of Pure and Applied Mathematics of Mathematical Sciences, Vol. 1, No-2 (JulyDec 2008): pp117- 